\title{
Improving the Elderly's Mental Health by Using Public Open Spaces in Disadvantaged Urban Neighborhoods: Tehran, Iran
}

\author{
Azadeh Lak (D A_Lak@sbu.ac.ir) \\ Shahid Beheshti University \\ Parichehr Rashidghalam \\ Shahid Beheshti University
}

\section{Research Article}

Keywords: Public Open Spaces, Older Seniors, Mental Health, Urban Design, Disadvantaged Neighborhoods, Tehran, Iran

Posted Date: September 23rd, 2021

DOI: https://doi.org/10.21203/rs.3.rs-918642/v1

License: (c) (1) This work is licensed under a Creative Commons Attribution 4.0 International License. Read Full License 


\section{Abstract}

Background: Today, the beneficial impact of public open spaces(POS) on the mental and physical health of the elderly is considered worldwide. However, the knowledge about these effects on the mental health of older adults in disadvantaged urban neighborhoods, especially in developing countries, is still insufficient.

Methods: This study investigates the relationship between POS use and the mental health status of elderly residents in the disadvantaged neighborhoods of Tehran, the capital of Iran. The data on the frequency of use of public open spaces and the health status include ten items collected from 420 older adults of disadvantaged neighborhoods in District 10 of Tehran. We used exploratory factor analysis to explore the main factors of the elderly mental health in the disadvantaged neighborhood. Finally, the multivariate multiple regression model was used to determine the relationship between the frequency of POS use and mental health status among older seniors.

Results: These ten items identified two fundamental characteristics of mental health status, including "feeling worthless" and "social interaction," using exploratory factor analysis. "Feeling of worthlessness" was negatively significantly associated with the level of gender, marital, occupation, and education, as well as frequently attending in POS. "Social interaction" was influenced by gender, occupation, and marital status, as well as frequent use of POS. The results showed that the frequency of public open space use has a negative correlation with the feeling of worthlessness and a positive correlation with the older residents' social interactions and contacts.

Conclusion: According to the findings, increasing the more senior residents' access to public open spaces through planning can improve their mental health as well as their social interactions, especially in disadvantaged neighborhoods.

\section{Introduction}

The aging of the population has been accelerated because of increased life expectancy and falling fertility rates. It is predicted that until 2050 , the world population aged over 65 probably increases to nearly 1.5 billion, representing $16 \%$ of the world's population [1]. Because of the shifting age structure, better health and social care forms and changes in community infrastructures, mainly concerning social determinants of health, should be predicted and planned [2].

Older seniors, especially those who live in disadvantaged urban neighborhoods, often have less access to public open spaces because of the density of buildings, and consequently, older adults are more vulnerable to mental health issues such as depressive symptoms and stress[3-5]. An increase in the suicide rate [6] and the rate of dementia [7, 8]can be a direct consequence of mental health issues among the older residents and bring about the growth of social and economic costs to communities[1,9]. Therefore, it seems essential to focus all our attention on finding practical solutions because mental health issues among older adults can cause severe consequences for communities. 
Public open spaces(POS) have numerous health benefits, especially for the elder residents living in urban neighborhoods [10]. Based on the findings of recent studies, there seems to be a relationship between health (physical and mental) and the existence of POS in neighborhoods for older residents [11-13]. POS and green spaces can help promote mental health by inducing physical activity[12], social interaction[14, 15], and contact with nature[15]. At the same time, green spaces can decrease psychological stress [16]. Furthermore, based on the findings of recent studies, it has been confirmed that the mental health of those who live in the residential area with POS and greenery, providing physical, social, and economic effects on older adults, is in a better condition in comparison with those who do not have access to POS $[10,15,17]$.

Taking all these benefits of POS into account, urban planners, designers, and policymakers have focused on designing and providing adequate POS and green areas to the elderly [10, 15-17].

In Iran, it is predicted that the population aged over 65 years will increase from $9.3 \%$ in 2016 to $18 \%$ in 2040[18]. Accordingly, planning for providing more access to POS is regarded as a priority, but this is not a priority for local authorities in many developing countries, especially in disadvantaged neighborhoods [19]. Furthermore, it's worth noting that although the effects of POS on the mental health of the elder adults living in the urban neighborhoods are investigated and studied before [20], is this topic has not been addressed adequately in the studies conducted in the context of the developing countries such as Iran [21]. In addition, limited studies have examined the relationship between the frequency of use of POS and the mental health status of older adults in disadvantaged urban neighborhoods.

This study employs a social-ecological model of health[22] to determine the relationship between the use of POS and mental health. This relationship can be determined by psychosocial factors and the frequency of public open space use in the disadvantaged neighborhoods of Tehran. Our findings indicated that the frequency of public open space use has a negative relationship with the feeling of worthlessness and a positive relationship with the older residents' social interactions and contacts in the deprived neighborhoods of Tehran. Therefore, the purpose of this study is to address this gap in previous studies and to investigate the relationship between the frequency of use of POS and the mental health status of the older adults in the disadvantaged urban neighborhoods of district 10 Tehran, the capital of Iran.

\section{Methods}

\subsection{Field study}

This study tried to explore the effects of using public open spaces on the mental health status of older adults in disadvantaged urban neighborhoods. District 10 in Tehran is a practical case for this research because its POS has been under maximum pressure due to recent developments, urban expansion, and rising population and land prices. To achieve this goal, the urban neighborhoods of District 10 of Tehran, with a gross urban density of 396 people per hectare and an average net residential density in the district 
of 700 people per hectare was selected as the case study area (Fig. 1). The population of this urban district increased to $31.1 \%$ during 1996-2016. During recent urban development, green spaces have decreased by about $15 \%$ [23]. This reduction poses a range of risks to older residents, including the mental health issues addressed in the previous studies. The findings of this study can provide helpful evidence for the local authorities about the value of POS for older adults. Figure 1 shows the neighborhoods of District 10 and its compact fabric.

\section{Procedure}

The researcher gathered the primary data to explore the association between mental health status and POS use among older adults. The older residents over 65 in the 10 neighborhoods of District 10 of Tehran were chosen as the statistical population of this study (Fig. 1). The sampling method used in this study was purposeful sampling (non-random sampling). The sampling method used in this study was purposeful sampling (non-random sampling). Initially, all older residential blocks in the 10 neighborhoods of District 10 of Tehran were mapped in the geographic information system (GIS), and four residential blocks were randomly selected from each neighborhood. All households in 40 older residential blocks were obtained from each neighborhood's health center and used as the sampling framework in district 10. Then, about 45 individuals from each neighborhood of District 10 were purposefully chosen for data collection. If the selected individuals did not answer the questions, other individuals would be randomly chosen and surveyed.

\subsection{Survey instrument}

The data were collected with the use of a questionnaire. The questionnaire designed consisted of 17 questions and was divided into two parts. The first part consisted of 7 questions related to the sociodemographic status of the participants [24]and the frequency of their use of public open spaces. The second part consisted of 10 questions about the mental health status of the elderly [25]. Previous studies conducted by other researchers have used the same questions in their questionnaires with acceptable reliability and validity. The face validity and reliability of the questions were evaluated in this study.

\subsection{Data collection procedures}

A total of 420 elder residents (people above 65 years old) with health documents in the neighborhoods' health centers in District 10 of Tehran organized the sample chosen through purposeful sampling (nonrandom sampling). These participants answered the questionnaire in August and September 2019 (Table 1). Those older residents who suffered from severe physical problems and communication difficulties were purposefully excluded from this study. Five trained interviewers performed face-to-face interviews. The Ethics Board of the Iran University of Medical Sciences (IUMS) granted the ethical approval of this study. All those who have participated in this study have formally consented to it. 
Table 1

Participants based on their gender, marital status, education, and occupation

\begin{tabular}{|llll|}
\hline \multirow{3}{*}{ Gender } & Variables & Number & Percentage \\
& Male & 220 & $(52 \%)$ \\
& Female & 200 & $(48 \%)$ \\
& Single & 78 & $(2 \%)$ \\
& Widow & 91 & $(30 \%)$ \\
& Married & 251 & $(68 \%)$ \\
& Lower than high school & 198 & $(47 \%)$ \\
& High school & 156 & $(37 \%)$ \\
& Academic & 66 & $(16 \%)$ \\
\multirow{2}{*}{ Occupation } & Employed & 50 & $(12 \%)$ \\
& Housewife & 122 & $(29 \%)$ \\
& Retired & 248 & $(59 \%)$ \\
\hline
\end{tabular}

\subsection{Research variables}

\subsubsection{Exposure variable}

This study used the frequency of use of public open spaces as exposure to green spaces. It can be regarded as an independent variable widely applied in health studies because it's associated with positive health results[26-28]. Three classes of frequency of public open space attendance were initially being differentiated, as shown in Table 2. Besides this variable, four socio-economic factors (i.e., gender, marital status, educational status, and occupation) were also used in the analysis, as shown in Table 1. 
Table 2

Exposure variable according to the frequency of POS use used to collect data

\begin{tabular}{|llll|}
\hline & Classes & Frequency of public open space use & Percentage \\
\hline Rarely & Once in a month & 72 & 17 \\
\cline { 2 - 4 } & Once in a fortnight & 89 & 21 \\
\hline Infrequently & Once a week & 119 & 28.5 \\
\hline Frequently & Two days or more in a week & 94 & 23.5 \\
\cline { 2 - 4 } & Everyday & 46 & 11 \\
\hline Total & & 420 & 100 \\
\hline
\end{tabular}

\subsubsection{Outcome variables}

According to examining the effect of POS use on the mental health status of older people in disadvantaged neighborhoods. The mental health status of the older residents was employed as an outcome variable. The older residents' mental health status can be regarded as the outcome variable in the present study. However, considering the findings of previous studies, there are numerous methods through which it's possible to measure mental health status, including epilepsy, psychoses, dementia, depression, and suicide among the older residents[25]. We used ten statements/items, measured on a 4point Likert scale (i.e., None $=0$. Low $=1$, Moderate, $=2$ High $=3$ ), to specify the participants' mental health status shown in Table 3. It is worth mentioning to consider that more than $40.2 \%$ of the participants answered with "none," 31.7\% responded with "low", 16.8\% answered with "moderate", and $11.3 \%$ answered with "high".

Based on initial correlation analysis, there are higher-level correlations among the 10 items. The researcher decided to conduct an exploratory factor analysis employing the scores associated with these items to moderate the dimensionality of data and get to a more reliable set of dimensions [29]. In this regard, we employed "the principal axis factoring with the oblique rotation method to extract the factors". The analysis identified two symptoms as 'feeling of worthlessness' and 'social interaction', which had more than one factor. We decided to put these items aside and rerun the factor analysis. None of the items had high loadings on more than one factor, according to our study.

The result of the exploratory factor analysis included 'feeling of worthlessness' and 'social interaction', reflecting the mental health status of the elder participants (Table 4). Then, we conducted the regression method to generate the scores of these two factors. This method helps assess factor scores with a mean of 0 and a variance equal to the squared multiple correlations between the estimated factor scores and the valid factor values [29]. Finally, we analyzed the extracted factor scores to assess the association of POS use on the older residents' mental health status in the deprived neighborhoods.

\subsection{Data analysis}


We conducted the multivariate multiple linear regression model in SPSS v.21, in which a group of independent variables controls a set of dependent variables. The results showed a negative correlation (0.685 ) between the extracted factors (outcome variables) in the process of factor analysis. Regarding this negative correlation, if the elderly person suffers from the 'feeling of worthlessness' (factor 1), he is less likely to have 'social interaction' (factor 2).

\section{Table 3}

\section{The frequency of responses to mental health status items extracted from the [25]}

Items
Percentage of the participants

None Low Moderate High Total

Q1." Changes in appearance or dress, or problems maintaining the home or yard."

Q2."Confusion, disorientation, problems with concentration or decision-making"

Q3." Decrease or increase in appetite; weight changes."

Q4." Depressed mood lasting longer than two weeks."

Q5." Feeling of worthlessness, inappropriate guilt, helplessness; thoughts of suicide (life satisfaction)."

Q6.” Memory loss, especially recent or short-term memory problems."

Q7." Physical problems that can't otherwise be explained: aches, constipation, etc."

Q8." Social withdrawal; loss of interest in things that used to be enjoyable (Withdrawal from friends and activities)."

Q9." Trouble handling finances or working with numbers."

Q10. "Unexplained fatigue, energy loss or sleep changes"

Average
37

33

31

37

34

39

32

68

68

41

50

40.2

50

39

14

30

20

29

22

40

15

31

21

35

18

38

23

19

8

25

16

18

100

31

11

8

100

The estimation was done in two stages. First, we conducted an auxiliary instrumenting equation to derive where "frequency of POS use" was regressed on all the exogenous variables together with the items. Second, we used the OLS model to estimate the predicted values of "the frequency of POS use" instead of the original values to regress the older adults' mental health status. We also conducted the test of WuHausman and Durbin in order to ensure if "the frequency of POS use" is an exogenous variable[29]; that is, it does not suffer from endogeneity bias. The results confirmed the null hypothesis that "the frequency 
of POS use" is an exogenous variable. Factor 1 gained the Durbin test $\chi^{2}=0.62, p=0.42$; Wu-Hausman F test $=0.65, p=0.41$, and factor 2 was estimated as Durbin test $\chi^{2}=0.25, p=0.59$ and; Wu-Hausman $F$ test $=0.31, p=0.61$.

Table 4

the results of Mental health items and factors

\begin{tabular}{|llll|}
\hline Items & Feeling of worthlessness & Social interaction & Communalities \\
\hline Q1 & 0.680 & -0.121 & 0.579 \\
\hline Q2 & 0.669 & -0.072 & 0.441 \\
\hline Q4 & 0.6982 & -0.312 & 0.362 \\
\hline Q5 (removed) & 0.656 & -0.164 & 0.573 \\
Q6 & 0.395 & -0.361 & 0.423 \\
\hline Q7 & -0.052 & -0.851 & 0.668 \\
\hline Q8 & 0.061 & -0.817 & 0.733 \\
\hline Q9 & 0.031 & -0.690 & 0.605 \\
\hline Q10 (removed) & -0.016 & -0.598 & 0.372 \\
\hline variance Percentage & 39.45 & -0.416 & 0.522 \\
\hline Extraction method: Principal axis factoring; Rotation method: Oblique with Kaiser normalization \\
\hline
\end{tabular}

\section{Results}

Table 5 is shown the results of the multivariate multiple regression process. It can be concluded that the overall model was demonstrated statistical significance. Each factor model was validated as an acceptable level of explanatory power and is statistically significant. These models can justify $45 \%$ and $31 \%$ variations in "feeling of worthlessness" and "social interaction" items. The analysis shows that these two models demonstrate that "frequency of POS use" is a significant explanatory factor for "feeling of worthlessness" as well as "social interaction". Based on model 1, "feeling of worthlessness" is likely to be reduced by an increasing frequency of POS use. On the other hand, "social interaction" is likely to be increased by a growing frequency of public open space use. 
Table 5

multivariate multiple regression analyses reporting standardized beta according to the effect of POS use on the elderly's mental health status in disadvantaged neighborhoods

\begin{tabular}{|lllll|}
\hline & \multicolumn{2}{l}{ Feeling of worthlessness } & \multicolumn{2}{l|}{ Social interaction } \\
& $\mathbf{R}^{2}$ :.451 & & $\mathbf{R}^{2}$ :.305 & \\
\hline & standardized beta & P-value. & standardized beta & P-value. \\
\hline Rarely & 0.343 & $<0.05$ & -0.672 & 0.43 \\
\hline Low & -0.681 & 0.52 & 0.591 & 0.35 \\
\hline Frequently & -0.782 & $<0.01$ & 0.764 & $<0.01$ \\
\hline Married & -0.472 & $<0.01$ & 0.376 & $<0.01$ \\
\hline Female & -0.123 & $<0.01$ & 0.137 & $<0.05$ \\
\hline Employed & -0.483 & $<0.05$ & 0.429 & $<0.05$ \\
\hline Education & 0.357 & $<0.05$ & -0.361 & 0.34 \\
\hline
\end{tabular}

In multivariate multiple regression analyses, the feeling of worthlessness among older adults was significantly negatively associated with being female, employed, employed, and frequently attending in POS (Table 5). Having "Social interaction" was influenced by the most significant independent variables, including gender (being female), having a job, and marital status. "Social interaction" was influenced positively by the frequent use of POS. This variable was negatively statically significant with rarely use of POS among the elderly in disadvantaged neighborhoods (Table 5).

\section{Discussion}

This study attempts to examine the relationship between the POS use and status of mental health among older residents in disadvantaged urban neighborhoods in Tehran, Iran. Due to the importance of the elderly mental health in underprivileged neighborhoods in international studies[30,31], the lack of empirical evidence on disadvantaged urban neighborhoods, especially in the context of developing countries and Iran[32], calls the reliability and the wide application of such findings into question. The issue of mental health and use of POS is of particular significance in regard to the older residents, particularly in poor urban areas[30,31]. Accordingly, this study used data on the mental health status of the more senior adults (420 elder residents) in the disadvantaged urban neighborhoods and their use of POS in District 10 in Tehran. It confirmed that the frequency of POS use might reduce mental health symptoms in older adults(feeling of worthiness) and increase their social interactions. In particular, in the absence of a database of the prevalence of mental disorders in the Iranian elder residents, this study provided a helpful perspective on promoting the health of the older adults (physical and mental) for policymakers, urban planning, and designing experts. The findings of the previous studies also show that POS use can increase the mental health status of the older residents as well as their social 
interactions[33,34]. However, one of the problems of disadvantaged neighborhoods is the lack of adequate access to open spaces suitable for older residents. This issue requires the availability of green spaces and POS to increase their attendance for the more aged residents according to their environmental preferences $[15,17,35]$.

The results of regression analysis of this study showed that the more the older residents attend POS, the less they suffer from the feeling of worthlessness and dissatisfaction with their lives and the more their social interactions and active presence in communities (being with friends, family, and social groups) will be. The studies conducted on the older residents show that an increase in the more senior residents' social capital and social interactions can contribute to a healthy life and a successful aging process, leading finally to social health $[15,17]$. However, this study showed that the older adults' social interaction and social health outcomes from their presence in the community and having physical activity. The study conducted by Schmidt et al.(2019) shows that when the older residents are engaged in social interaction, they are less inclined to walk, so their physical activity and physical health are less affected, but their mental health improves. This study also showed that the feeling of self-esteem in the older residents and their social performance are the consequence of and are reciprocally related to their mental health. A previous study conducted in Tehran also showed that based on the regression model results, variables such as gender, age, education, having a job, life satisfaction, and physical-movement limitation are significantly related to the mental health of Iranian older adults [21]. Social participation is the essential factor in the mental health of the elderly in Iran [36].

Another finding of this study indicates that in disadvantaged urban neighborhoods, older women are more inclined to attend POS and have a better mental health status together with a sense of worthiness in their social interactions. This finding is consistent with Koohsari et al.(2019) study showed that the Japanese elder women who are more present in neighborhoods' spaces have better mental health conditions in terms of depression.

Furthermore, our study revealed that those older residents who are married, employed, and more educated have better mental health status. Although they live in disadvantaged urban neighborhoods, they are more present in their neighborhoods' POS, have more interactions with other people, and are more inclined to have social relationships. The reason behind this can be the higher level of self-confidence and self-esteem among these older residents.

Status of the elderly. Due to the insufficiency of appropriate POS in disadvantaged neighborhoods, our findings emphasize the importance of identifying older residents vulnerable to mental health issues based on demographic and social characteristics and the direct relationship between the proportion of POS and green spaces and the mental health status of older urban residents. The relation between The mental health outcomes, the ratio of green spaces, and the Sociodemographic status of the neighborhood was proved[30].

In recent years, the design and planning interventions aimed at reducing older residents' health costs save been focused on promoting "active aging" spaces [37] and "aging in place" [38]. This type of intervention 
emphasizes more opportunities to use POS in neighborhoods[37]. Many studies have shown a positive association between creating POS and green spaces and mental health benefits[3, 39-42]. According to the quality of neighborhoods on the older people's mental health[40], improving the neighborhood's characteristics can lead to the social integration of older residents and higher social interactions [42-44]. Improving the neighborhood's quality needs greater attention in disadvantaged urban neighborhoods due to the high density and the lack of sufficient POS as well as population density, deteriorated built environment, and sociodemographic status of residents[45]. Therefore, in this study, we sought to examine the factors affecting the mental health of older urban residents (depression symptoms) and consider the effects of specific sociodemographic factors and POS use such as streets, squares, and local parks.

The findings of this study provide significant empirical data on planning and designing policies for "aging in place" in disadvantaged urban neighborhoods. Therefore, designing and planning urban spaces for vulnerable groups in terms of mental health and developing POS in disadvantaged neighborhoods based on the preferences and demands of the older residents should become a priority. This approach can encourage more senior residents to increase their attendance and use of POS. Meeting operational needs (appropriate density, land use mixing, green spaces in streets and squares, safety, proper flooring, lighting, proper landscape, environmental design), attending to environmental preferences (security against crime, landslides, and getting lost), and holding social and cultural events are among the factors that can improve the quality of public open spaces in neighborhoods. In addition, social interaction within neighborhoods' public open spaces and parks can promote health and wellbeing [46] [47]. As a result, when social interactions occur in a public setting, positive psychological changes can occur in older people through mutual understanding and interests[30].

The limitations of this study should be taken into consideration for interpreting the results of this study: (a) Although the minimum sample size requirement is observed in the present study, additional insights could be obtained by surveying more people - especially when it is considered that a limited sample with mental health problems were involved in this study; (b) Although the employed terms could accurately convey the message, it's not generally proper to conceptualize people with terms such as "feeling of worthlessness", and "social interaction"; (c) The present study only concentrated on a specific period; however, in order to get to more reliable and generalizable results, a longitudinal study with the same sample seems to be necessary. Our future studies can concentrate on solving these problems, investigating the possible correlation between the use of public open spaces and mental health status based on the specific characteristics of public open spaces in disadvantaged neighborhoods, and gaining a more comprehensive insight into the participants' perceptions about public open spaces.

\section{Conclusion}

This study revealed that the sense of worthiness and inclination for more excellent social interactions are significantly associated with POS use among older adults in disadvantaged urban neighborhoods. However, the findings also stated that the greater the attendance and use of POS in impoverished urban 
neighborhoods is, the less the symptoms of mental health disorders, mainly depression, will be among older residents of disadvantaged neighborhoods. The result of previous cross-sectional urban design studies indicates that active presence in public open spaces in urban neighborhoods positively correlates with the mental health status of older residents. In addition, due to the mutual effects of POS and increasing physical and social activities and consequently, improving the mental health status of older residents, this study emphasized the importance of more senior residents' presence in and positive use of POS and green spaces of the cities for improving their health status.

\section{Abbreviations}

POS: Public Open spaces

WHO: World Health Organization

\section{Declarations}

\section{- Ethics approval and consent to participate}

This study was approved by the Iran University of Medical Sciences Ethical Review Board (Ethics Code Number; IR.IUMS.REC.1397.148). All participants gave verbal consent to participate in the study. An overseeing mental health expert ruled that all participants were capable of ethically and medically consenting to their participation in the research presented in this manuscript. Moreover, all methods were performed in in accordance with the Declaration of Helsinki and must have been approved the Iran University of Medical Sciences Ethical Review Board (Ethics Code Number; IR.IUMS.REC.1397.148).

\section{-Consent for Publication:}

Not applicable.

\section{-Availability of Data and Materials:}

The datasets used and/or analysed during the current study available from the corresponding author on reasonable request.

\section{-Competing Interests:}

The authors declare that they have no competing interests.

\section{-Funding:}


The authors received no financial support for this research study.

\section{-Authors' Contributions:}

AL designed the scoping review and conducted the searches. AL and PR have analysed a statistical survey and drafted the manuscript with editorial and content input from all other authors. All authors have read and approved the final version of the paper.

\section{References}

1. WHO WHO (2015) WHO | Global health and ageing

2. Beard JR, Officer A, Carvalho IA de, et al (2016) The World report on ageing and health: a policy framework for healthy ageing. Lancet (London, England) 387:2145. https://doi.org/10.1016/S01406736(15)00516-4

3. Kim J-H, Gu D, Sohn W, et al (2016) Neighborhood Landscape Spatial Patterns and Land Surface Temperature: An Empirical Study on Single-Family Residential Areas in Austin, Texas. Int J Environ Res Public Health 13:880. https://doi.org/10.3390/ijerph13090880

4. Nordin N, Nakamura H (2020) The Influence of the Objective and Subjective Physical Neighbourhood Environment on the Physical Activity of Older Adults: A Case Study in the Malaysian Neighbourhoods of Johor Bahru. Sustainability 12:1760

5. Okkels N, Kristiansen CB, Munk-Jørgensen P, Sartorius N (2018) Urban mental health: challenges and perspectives. Curr Opin Psychiatry 31:258-264

6. Dupéré V, Leventhal T, Lacourse E (2009) Neighborhood poverty and suicidal thoughts and attempts in late adolescence. Psychol Med 39:1295-1306

7. Langa KM (2015) Is the risk of Alzheimer's disease and dementia declining? Alzheimers Res Ther 7:. https://doi.org/10.1186/S13195-015-0118-1

8. K D, MP van B, OJ S, et al (2015) Target risk factors for dementia prevention: a systematic review and Delphi consensus study on the evidence from observational studies. Int J Geriatr Psychiatry 30:234246. https://doi.org/10.1002/GPS.4245

9. Wimo A, Guerchet M, Ali G-C, et al (2017) The worldwide costs of dementia 2015 and comparisons with 2010. Alzheimer's Dement 13:1. https://doi.org/10.1016/J.JALZ.2016.07.150

10. Lak A, Aghamolaei R, Baradaran HR, Myint PK (2020) A Framework for Elder-Friendly Public Open Spaces from the Iranian Older Adults' perspectives: A Mixed-Method Study. Urban For Urban Green 126857. https://doi.org/10.1016/j.ufug.2020.126857

11. Aspinall PA, Thompson CW, Alves S, et al (2010) Preference and relative importance for environmental attributes of neighbourhood open space in older people. Environ Plan B Plan Des 37:1022-1039. https://doi.org/10.1068/b36024 
12. Astell-Burt T, Feng X, Kolt GS (2013) Mental health benefits of neighbourhood green space are stronger among physically active adults in middle-to-older age: evidence from 260,061 Australians. Prev Med (Baltim) 57:601-606

13. Andreucci MB, Russo A, Olszewska-Guizzo A (2019) Designing urban green blue infrastructure for mental health and elderly wellbeing. Sustainability 11:6425

14. Loukaitou-Sideris A, Levy-Storms L, Chen L, Brozen M (2016) Parks for an Aging Population: Needs and Preferences of Low-Income Seniors in Los Angeles. J Am Plan Assoc 82:236-251. https://doi.org/10.1080/01944363.2016.1163238

15. Wen C, Albert C, Von Haaren C (2018) The elderly in green spaces: Exploring requirements and preferences concerning nature-based recreation. Sustain Cities Soc 38:582-593

16. Koohsari MJ, McCormack GR, Nakaya T, et al (2019) Urban design and Japanese older adults' depressive symptoms. Cities 87:166-173

17. Levy-Storms L, Chen L, Loukaitou-Sideris A (2018) Older Adults' Needs and Preferences for Open Space and Physical Activity in and Near Parks: A Systematic Review. journals.humankinetics.com. https://doi.org/10.1123/japa.2016-0354

18. miri neda, Maddah M, Raghfar H (2019) The Effects of Population Aging on Economic Growth of Iran through the fertility rate and life expectancy (Overlapping Generation Model Approach) TT. Yektaweb_Journals 19:287-324

19. Irandoost K, Doostvandi M, Litman T, Azami M (2019) Placemaking and the right to the city of urban poor: a case studyin Sanandaj, Iran. J Place Manag Dev JPMD-03-2018-0027. https://doi.org/10.1108/JPMD-03-2018-0027

20. Wu Y-T, Prina AM, Jones A, et al (2015) Older people, the natural environment and common mental disorders: cross-sectional results from the Cognitive Function and Ageing Study. BMJ Open 5:e007936

21. Alavi M, Jorjoran Shushtari Z, Noroozi M, Mohammadi Shahboulaghi F (2018) Mental health and related factors in old population in Tehran 2014-2015. J Maz Univ Med Sci 27:112-122

22. Reupert A (2017) A socio-ecological framework for mental health and wellbeing

23. Municipality T (2020) Atlas of Tehran Metropolis. Tehran; 2018

24. Lak A, Aghamolaei R, Baradaran HR, Myint PK (2019) Development and validation of elder-friendly urban spaces questionnaire (efusq). BMC Geriatr 19:. https://doi.org/10.1186/s12877-019-1355-0

25. World Health Organization. Regional Office for South-East (2020) Integrated care for Older People (ICOPE): a manual for nurses (trainee's handbook). World Health Organization. Regional Office for South-East Asia, New Delhi PP - New Delhi

26. Paquet C, Orschulok TP, Coffee NT, et al (2013) Are accessibility and characteristics of public open spaces associated with a better cardiometabolic health? Landsc Urban Plan 118:70-78. https://doi.org/10.1016/J.LANDURBPLAN.2012.11.011 
27. De Vries S, Verheij RA, Groenewegen PP, Spreeuwenberg P (2003) Natural environments-healthy environments? An exploratory analysis of the relationship between greenspace and health. Environ Plan A 35:1717-1731

28. L W, P H, S F, F B (2017) Public green spaces and positive mental health - investigating the relationship between access, quantity and types of parks and mental wellbeing. Health Place 48:6371. https://doi.org/10.1016/J.HEALTHPLACE.2017.09.002

29. Yigitcanlar T, Kamruzzaman M, Teimouri R, et al (2020) Association between park visits and mental health in a developing country context: The case of Tabriz, Iran. Landsc Urban Plan 199:103805

30. Lee HJ, Lee DK (2019) Do Sociodemographic Factors and Urban Green Space Affect Mental Health Outcomes Among the Urban Elderly Population? Int J Environ Res Public Health 16:789. https://doi.org/10.3390/ijerph16050789

31. Smith RJ, Lehning AJ, Kim K (2018) Aging in place in gentrifying neighborhoods: Implications for physical and mental health. Gerontologist 58:26-35

32. Fassihi H, Shamaei A, Azarakhsh F (2020) Analysis of access to urban parks with the approach of spatial justice (study sample: Ilam city). Spat Plan 10:105-118

33. Cole R, Koohsari MJ, Carver A, et al (2019) Are neighborhood environmental attributes more important for older than for younger adults' walking? Testing effect modification by age. J Aging Phys Act 27:354-359

34. Schmidt T, Kerr J, Schipperijn J (2019) Associations between neighborhood open space features and walking and social interaction in older adults-a mixed methods study. Geriatr 4:. https://doi.org/10.3390/geriatrics4030041

35. Lak A, Aghamolaei R, Baradaran HR, Myint PK (2020) A Framework for Elder-Friendly Public Open Spaces from the Iranian Older Adults' perspectives: A Mixed-Method Study. Urban For Urban Green. https://doi.org/10.1016/j.ufug.2020.126857

36. Rashedi V, Gharib M, Yazdani AA (2014) Social Participation and Mental Health among Older Adults in Iran TT -. Iranian-Rehabilitation-Journal 12:9-13

37. Lak A, Rashidghalam P, Myint PK, Bradaran HR (2019) Comprehensive 5-P framework for active ageing through ecological approach: an iterative systematic review

38. Wiles JL, Leibing A, Guberman N, et al (2012) The meaning of "aging in place" to older people. Gerontologist 52:357-366

39. GJ N, SK N, S R, et al (2006) Community Design and Access to Recreational Facilities as Correlates of Adolescent Physical Activity and Body-Mass Index. J Phys Act Health 3:S118-S128. https://doi.org/10.1123/JPAH.3.S1.S118

40. RJJ J, J T (2008) Environment shapes health, including children's mental health. J Am Acad Child Adolesc Psychiatry 47:129-131. https://doi.org/10.1097/CHI.0B013E31815D6944

41. Hu XR, Kang HL, Li Y, et al (2015) Direct copolycondensation of biobased elastomers based on lactic acid with tunable and versatile properties. Polym Chem 6:8112-8123.

https://doi.org/10.1039/c5py01332a

Page 15/17 
42. Wang Z, Shepley MM, Rodiek SD (2012) Aging in Place at Home Through Environmental Support of Physical Activity: An Interdisciplinary Conceptual Framework and Analysis.

http://dx.doi.org/101080/027638932011625289 26:338-354.

https://doi.org/10.1080/02763893.2011.625289

43. Pleson E, Nieuwendyk LM, Lee KK, et al (2014) Understanding Older Adults' Usage of Community Green Spaces in Taipei, Taiwan. Int J Environ Res Public Health 11:1444. https://doi.org/10.3390/IJERPH110201444

44. Sarkar C, Gallacher J, Webster C (2013) Urban built environment configuration and psychological distress in older men: Results from the Caerphilly study. BMC Public Health 13:695. https://doi.org/10.1186/1471-2458-13-695

45. Grant TL, Edwards N, Sveistrup H, et al (2010) Inequitable walking conditions among older people: examining the interrelationship of neighbourhood socio-economic status and urban form using a comparative case study. BMC Public Health 10:1-16

46. Maller C, Townsend M, Pryor A, et al (2006) Healthy nature healthy people: "contact with nature" as an upstream health promotion intervention for populations. Health Promot. Int. 21:45-54

\section{Figures}




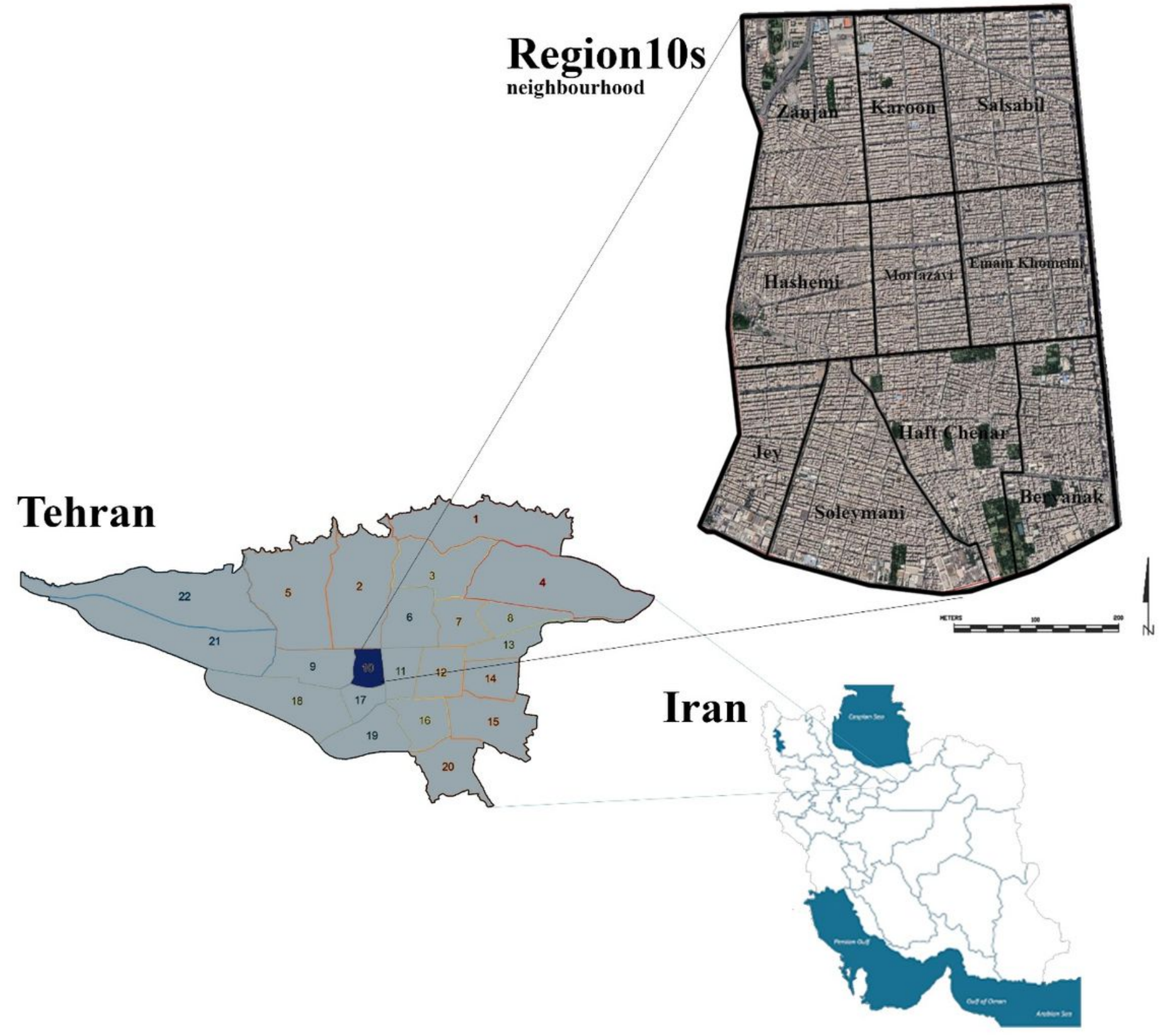

Figure 1

Neighborhoods of District 10 of Tehran municipality (strategic area) 